\title{
Articulação em redes como um processo de construção de significado para o fortalecimento do turismo de base comunitária
}

Articulation in networks as a process of constructing meaning for the strengthening of community-based tourism

Articulación en redes como un proceso de construcción de significados para el fortalecimiento del turismo de base comunitaria

http://dx.doi.org/10.18472/cvt.16n2.2016.1173

Debora Goes Urano 〈debby104@hotmail.com >

Mestranda do Programa de Pós-Graduação em Turismo da Universidade Federal do Rio Grande do Norte, UFRN, Brasil.

Felipe de Souza Siqueira 〈felipesiqueira5o@gmail.com >

Professor da Faculdade do Vale do Jaguaribe, FVJ, Brasil.

Wilker Ricardo de Mendonça Nóbrega 〈wilkernobrega@yahoo.com.br >

Professor e pesquisador do Departamento de Turismo da Universidade Federal do Rio Grande do Norte, UFRN, Brasil

CRONOLOGIA DO PROCESSO EDITORIAL

Recebimento do artigo: 16 de novembro de 2015

Aceite: $\mathbf{2 8}$ de julho de 2016

FORMATO PARA CITAÇÃO DESTE ARTIGO

URANO, D. G.; SIQUEIRA, F. S.; NÓBREGA, W. R. M. Articulação em redes como um processo de construção de significado para o fortalecimento do turismo de base comunitária. Caderno Virtual de Turismo. Rio de Janeiro, v. 16, n. 2, p. 200-210, ago. 2016.

$$
\text { REALIZAÇÃO }
$$

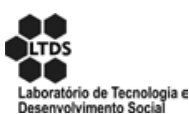

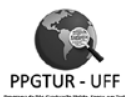

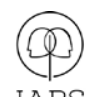

APOIO INSTITUCIONAL

EDIÇÃO

PATROCÍNIO

COPPE

UFR] 


\section{RESUMO}

Diversas iniciativas de turismo de base comunitária vêm buscando, como estratégia para o seu fortalecimento, a articulação por meio da formação de redes. O presente trabalho examina essas redes a partir de uma abordagem teórica, realizada por meio de pesquisa bibliográfica apoiado em autores como Capra $(1996,2002)$, Castells $(1999,2013)$, Scherer-Warren $(2006,2007)$ e Rovere (1999); e pesquisa documental em materiais produzidos pela Rede Turisol e Rede Tucum. O estudo apresentou que as Redes de Turismo de Base Comunitária constituem redes sociais de contrapoder constituídas por diferentes níveis de colaboração. Nelas, as conexões ocorrem por meio de um processo de comunicação que cria um contexto de significados e valores comuns que permite que os diversos nós envolvidos construam um sentimento de identidade e pertencimento enquanto membro da rede, fortalecendo a luta por um outro modelo de organização do turismo.

Palavras-chave: Redes Sociais. Redes de Contrapoder. Redes de Turismo de Base Comunitária.

\section{ABSTRACT}

Several community-based tourism initiatives have sought, as a strategy for their strengthening, the articulation through the formation of networks. This paper examines these networks from a theoretical approach, carried out through bibliographical research supported by authors such as Capra (1996, 2002), Castells (1999, 2013), Scherer-Warren $(2006,2007)$ and Rovere (1999); and documentary research in materials produced by Turisol Network and Tucum Network. The study showed that networks of community-based tourism are social networks of counter power consisting of different levels of collaboration. In them, the connections occur through a process of communication that creates a context of meanings and common values which allows the various nodes involved to build a sense of identity and belonging as a member of the network, strengthening the fight for another organization model of tourism.

Keywords: Social Networks. Networks of counter power. Based-Community tourism networks.

\section{RESUMEN}

Varias iniciativas del turismo de base comunitaria están buscando, como estrategia para su fortalecimiento, articulación por medio de la creación de redes. El presente trabajo examina estas redes desde un enfoque teórico, realizado a través de la investigación bibliográfica apoyada en autores como Capra (1996, 2002), Castells (1999, 2013), Scherer-Warren (2006, 2007) y Rovere (1999), así como de la investigación documental en materiales producidos por la Red Turisol y la Red Tucum. Este estudio presentó que las redes de turismo de base comunitaria se constituyen en redes sociales de contrapoder, compuestas de diferentes niveles de colaboración. En ellas, las conexiones se producen debido a un proceso de comunicación que crea un contexto de significados y valores comunes, los cuales permiten a los múltiples nodos implicados construir un sentido de identidad y pertenencia como miembro de la rede, fortaleciendo la lucha por otro modelo de organización del turismo.

Palabras clave: Redes sociales. Redes de contrapoder. Redes de turismo de base comunitaria. 


\section{INTRODUÇÃO}

O turismo de base comunitária surge a partir da necessidade de construção de um modelo de turismo alternativo ao turismo convencional. Propõe-se a ser um modelo de organização da atividade turística que coloca a comunidade como centro do processo de planejamento e organização do turismo. Nele, a população local é detentora e gestora dos equipamentos turísticos, participando efetivamente das decisões sobre o desenvolvimento da atividade na comunidade (BURSZTYN et al., 2009; CORIOLANO, 2009; IRVING, 2009). Constitui um mecanismo de resistência de comunidades tradicionais ante um processo de desenvolvimento que prioriza o mercado globalizado (BURSZTYN et al., 2009; BURGOS; MERTENS, 2015), contribuindo na luta pelo território e na afirmação da identidade das comunidades receptoras (SANSOLO; BURSZTYN, 2009).

A partir do final do século XX, despontam inúmeras iniciativas de turismo de base comunitária, que buscam como estratégia para o seu fortalecimento a articulação por meio da construção de redes (BURGOS; MERTENS, 2015; BURSZTYN et al., 2009). Durante o Fórum Social Mundial de 2004, em Mumbai, o documento intitulado De Mumbai a Porto Alegre: Quem realmente se beneficia com o turismo? (2004, p.1), construído a partir do Grupo de Intervenções em Turismo, aponta que "o trabalho em rede está no centro das estratégias futuras para identificar áreas de preocupação comum, construir alianças com indivíduos, organizações e movimentos que dividem este pensamento, e influenciar agendas de política de turismo".

As redes de turismo de base comunitária criadas vêm promovendo discussões acerca dessa nova proposta de organização da atividade turística, além de estabelecer intercâmbios de vivências, lutas e desafios experimentados pelas comunidades. Como exemplo, pode-se citar a Rede Brasileira de Turismo Solidário e Comunitário (Rede Turisol) e a Rede Cearense de Turismo Comunitário (Rede Tucum).

O surgimento dessas redes e o trabalho que elas vêm desenvolvendo na articulação e fortalecimento do turismo de base comunitária requer tanto uma maior compreensão do sentido e relevância destas dentro do fenômeno turístico, quanto no processo de fortalecimento das comunidades. Do mesmo modo, requer um maior entendimento sobre a forma, o significado e os processos que dão vida às mesmas. A proposta deste artigo é, portanto, trazer uma discussão preliminar sobre redes de turismo comunitário, a fim de levantar pontos que possam servir para futuras análises do processo de formação e construção das redes de turismo comunitário. O presente estudo foi realizado por meio de pesquisa bibliográfica sobre textos, livros e artigos científicos que abordam o conceito de redes, além de dissertações que trabalham com o tema "rede de turismo comunitário"; e pesquisa documental, realizada em documentos publicados por essas redes, como relatório de encontros, cadernos de normas e material institucional.

\section{REDES SOCIAIS NA CONSTRUÇÃO DE UM CONTRAPODER}

A noção de rede vem sendo ressiginificada ao longo dos anos e utilizada em várias áreas do conhecimento para explicar e compreender estruturas, sejam estas biológicas, territoriais ou sociais. Na compreensão de Capra $(1996,2002)$, uma rede é uma teia de relações que conectam processos vitais, os quais serão distintos em diferentes níveis e dimensões. 
Dentro do campo das ciências sociais, a noção de redes compreende um conjunto finito de nós, sejam estes indivíduos, instituições ou comunidades, que estabelecem vínculos sociais ou conexões específicas (BURGOS; MERTENS, 2015; TOLKACH et al., 2013). Essas conexões ocorrem por meio da comunicação que envolverão múltiplos aspectos inerentes à condição humana (CAPRA, 2002; CASTELS, 2013). A rede social se regenera a cada comunicação realizada, pois à medida que a comunicação é estabelecida são produzidos pensamentos e significados na mente das pessoas. Quando a comunicação é recorrente, é construído um processo de realimentação que cria um sistema comum de valores, crenças e visão de mundo, ou seja, "um contexto comum de significado" (CAPRA, 2002, p. 86). Esse "contexto comum de significado" faz com que cada indivíduo adquira sua identidade enquanto membro ou nó da rede, estabelecendo um limite para a mesma, baseado no sentimento de pertencimento e lealdade do indivíduo, e que será sempre renovado a partir de novas comunicações (CAPRA, 2002). Dessa forma, são as conexões que dão significado à rede social, e essas conexões nada mais são do que vias de comunicação estabelecidas entre os nós. É a comunicação entre eles que permitirá a consolidação dos valores e significados que nortearão e coordenarão a construção dos vínculos de interdependência entre as partes em sinergia e equilíbrio.

As relações estabelecidas por meio da comunicação ocorrem em um padrão de organização não linear (CAPRA, 2002), ou seja, um nó da rede se conecta a mais de um nó, quando não, a todos os nós da rede, criando um complexo sistema de nós e conexões que dão forma à estrutura reticular. Os nós podem, também, se conectar a um ponto de fora que passará, então, a fazer parte da rede, criando um sistema aberto com grande poder de expansão. Quanto maior o número de nós conectados, maior será seu poder de multiplicação e seu campo relacional (MARTINHO, 2003).

Tendo em vista essa estrutura não linear complexa de relações entre os diversos nós, a rede social cria uma organização horizontal e descentralizada, ou seja, os nós estão interligados sem que haja uma hierarquia, permitindo um processo de comunicação capaz de se propagar por toda a rede e de retornar por meio da realimentação. Nesse sentido, ocorre um processo de autorregulação e auto-organização, que emerge a partir das relações construídas no processo de conexão realizada por meio da comunicação (CAPRA, 1996).

Apesar dessa organização horizontal e descentralizada e da capacidade de auto-organização, as redes sociais não estão desprendidas de relações de poder, as quais estão na essência da sociedade. Diante da capacidade do ser humano de afirmar suas preferências e com base nelas fazer suas escolhas, surgem os conflitos de interesses entre os indivíduos. O poder é o meio pelo qual esses conflitos de interesse são resolvidos, o que pode acontecer tanto de forma coercitiva, quanto compensatória ou, então, condicionada quando o conflito é resolvido por meio da persuasão ou educação (CAPRA, 2002). As relações estabelecidas entre os nós da rede estarão dessa forma permeadas por conflitos de interesse no qual o poder se materializa por meio da construção do contexto de significado comum e de sentimento de pertencimento estabelecido por meio da comunicação.

Com a revolução recente da informática e o processo de globalização, a sociedade mergulha em uma nova dinâmica baseada na estrutura em rede que serve como instrumento de um capitalismo ultra-avançado, baseado nos fluxos financeiros, de informação e poder (CASTELLS, 1999). Essas redes são formadas por nós, que são locais de conexão dos fluxos de bens, pessoas ou informações. No entanto, da mesma forma que conecta os elementos, ela exclui comunidades e territórios. Regiões se tornam insignificantes para o capital financeiro e são privadas de diversos fluxos e de infraestrutura tecnológica (DIAS, 1995; CASTELLS, 1999). A rede é, portanto, seletiva e ocorre de acordo com os interesses dos detentores do 
poder; são eles quem comandam e quem produzem uma racionalidade às redes que compõem a sociedade contemporânea, como as redes viárias, de comunicação, e financeiras (SANTOS, 2006; 2005).

No entanto, apesar do avanço das tecnologias terem possibilitado o avanço do capitalismo e processos de exclusão e desvalorização de grupos sociais e territórios, permitiu, também, uma maior comunicação e articulação da sociedade civil, o que levou ao estabelecimento de redes de intercâmbio e de empoderamento de diversas organizações e movimentos políticos populares (MARTINHO, 2003; SCHERER-WARREN, 2006; CAPRA, 2002). Essas são redes de contrapoder ${ }^{1}$ (CASTELLS, 2013) intencionalmente constituídas, que visam à construção e o fortalecimento de ações coletivas que confrontarão os interesses embutidos nas instituições sociais.

Scherer-Warren (2007) distingue dois conceitos que se referem a essa nova forma de articulação da sociedade civil, os coletivos em rede e as redes de movimentos sociais. Para a autora, coletivos em rede referem-se "a conexões em uma primeira instância comunicacional, instrumentalizada através de redes técnicas, de vários atores ou organizações, que visam difundir informações, buscar apoios solidários, ou mesmo estabelecer estratégias de ação conjunta" (SCHERER-WARREN, 2007, p. 35). Já as redes de movimentos sociais são

redes sociais complexas, que transcendem organizações empiricamente delimitadas, e que conectam, simbólica e solidaristicamente, sujeitos individuais e atores coletivos, cujas identidades vão se construindo num processo dialógico (SCHERER-WARREN, 2007, p. 36).

Nas redes de movimentos sociais predominam as ações coletivas estabelecidas a partir de vontades políticas bem definidas e comuns a todos os envolvidos. Elas são utilizadas, frequentemente, como mecanismos de estratégia dos movimentos sociais para a sua organização e ações por meio de relações mais horizontalizadas e democráticas (SCHERER-WARREN, 2007, p. 42). Em organizações em rede, pressupõe-se que o poder é diluído e distribuído entre os diferentes nós, os quais são investidos de confiança e poder para cumprir determinada função em prol da rede (MARTINHO, 2003). Entretanto, como visto anteriormente, a rede não é isenta de conflitos de interesses, mas trabalha com mecanismos democráticos de resolução de conflitos, de construção coletiva de consensos e de decisão compartilhada que possam permitir um autocontrole das decisões e ações da rede (MARTINHO, 2003).

Dentro de redes de contrapoder haverá pontos mais fortes que possuem uma maior influência na articulação e na proposição de ações e estratégia e que atuam como mediadores do processo organizativo. Esse processo de mediação, muitas vezes, se configura como sendo bastante relevante para o empoderamento das redes de movimento social (SCHERER-WARREN, 2006). É essencial, no entanto, que a rede trabalhe no sentido de construir um equilíbrio que possibilite a autonomia dos sujeitos envolvidos apesar da existência de pontos mediadores.

Teixeira (2002), em estudo sobre redes de política, ressalta que o trabalho em estruturas de rede impõe diversos desafios e destaca que algumas características das redes tanto podem ser vistas como vantajosas para o processo de gestão como também limitadoras da sua eficácia gerando dificuldades na gestão e no alcance de seus objetivos. No caso das redes sociais, podem-se destacar alguns pontos apresentados pela autora, como o processo de negociação ser bastante lento, a dificuldade no cumprimento dos objetivos,

\footnotetext{
1 Para Castells, as relações de poder estão na essência da sociedade, a qual é constituída pelos detentores do poder, que dominam as instituições sociais de acordo com seus valores e interesses, e por um contrapoder, que questiona as instituições sociais e luta para que seus valores e interesses possam ser representados.
} 
pois as responsabilidades são diluídas; a dinâmica flexível que pode levar ao afastamento ou saída de alguns nós; e a falta de critérios de participação da rede bem definidos pode levar à marginalização de alguns nós (TEIXEIRA, 2002, p. 12).

Para Rovere (1999), a constituição de redes permite uma organização mais flexível capaz de assumir as heterogeneidades dos diversos sujeitos constituintes destas. O autor aponta a existência de cinco níveis na construção de redes que permitem o acompanhamento do seu grau de profundidade. No primeiro nível, reconhecer, ocorre à percepção da existência do outro e a aceitação das diferenças e heterogeneidades. No segundo nível, conhecer, começa a necessidade de conhecer o outro e o interesse em entender sua percepção de mundo. No terceiro nível, colaboração, verificam-se vínculos de reciprocidade e mecanismos de colaboração e ajuda espontânea. No nível seguinte, pode-se observar um processo mais complexo e sistemático de ações de cooperação visando um objetivo comum. E no último nível, há um estreitamento nos acordos que permitem a partilha de recursos.

Assim, as redes de contrapoder são espaços de construção coletiva que precisam de um forte trabalho de articulação e comunicação para que haja a sinergia necessária e que criem vínculos de reciprocidade e mecanismo de colaboração que venham a garantir a construção de significados e valores comuns, assim como um sentimento de pertencimento de cada nó, permitindo o fortalecimento da luta, ideologias e objetivos.

\section{AS REDES NO CONTEXTO DO FENÔMENO DO TURISMO}

O fênomeno do turismo tem como base o deslocamento de indivíduos de forma temporária que possibilita a conexão de pontos distantes do espaço global, caracterizados por polos emissores e receptores de turismo e as zonas de transição, na qual há um fluxo contínuo de pessoas, capital, cultura, costumes e ideologias. Essas conexões são sustentadas pela colaboração de diversos atores sociais de interesses e papéis distintos e que constituem uma rede de relacionamentos, que contribui para o desenvolvimento da atividade turística.

Esses atores são ao mesmo tempo "ativos e passivos" (FRATUCCI, 2008) e influenciarão diretamente na territorialização dos espaços para o turismo, a qual ocorrerá de formas distintas, dependendo da forma como as relações de poder entre esses agentes se configuram dentro da rede formada pelo turismo. O turista, o mercado, o poder público e a comunidade local se destacam como principais atores sociais envolvidos nesse fenômeno. A forma como esses diferentes atores exercem seus papéis dentro dessa rede de relações e os vínculos estabelecidos entre eles são decisivos para determinar como o processo de desenvolvimento do turismo ocorrerá.

A rede criada com o desenvolvimento do turismo convencional segue os interesses dos grupos detentores do poder e acaba por excluir parte da população local, priorizando a iniciativa privada que comanda e controla, com a força do capital, a apropriação dos espaços pelo turismo. O turismo convencional é, nesse sentido, seletivo no que se refere aos espaços a serem conectados dentro da rede. Ele exclui localidades que não possuem vantagens comparativas e competitivas necessárias, ou seja, não possuem um valor para o capital financeiro, ou que resistem ao processo de apropriação dos seus territórios. No caso, quando são inseridas na rede do turismo, grande parte das comunidades se submete às relações de poder ditadas por aqueles que têm o controle da atividade, ou seja, o mercado e o Estado (muitas vezes guiados por políti- 
cas neoliberais). Os vínculos construídos entre os diversos atores são puramente comerciais e as relações baseadas no mercado.

A rede construída a partir do turismo de base comunitária compreende, por sua vez, uma nova configuração de interações dos seus nós. Possuem relações de poder distintas, os atores sociais exercem seus papéis de forma diferente e os vínculos devem ser construídos baseados em outros valores como cooperação, solidariedade, equidade e justiça. Na rede do turismo comunitário a comunidade passa a ter um papel mais incisivo no planejamento e desenvolvimento da atividade. A população local será a detentora e gestora dos equipamentos turísticos e definirá os rumos para o desenvolvimento da atividade no local. O mercado, quando participa, exerce um papel de parceiro da comunidade tendo como função a comercialização dos serviços oferecidos pela população local a partir de valores baseados na economia solidária, cooperação e sustentabilidade. O Poder Público é, em alguns casos, principalmente no Brasil, omisso no seu papel de estimular e gerenciar a sustentabilidade das redes de relacionamento que estruturam o turismo comunitário. O turista se relaciona de forma diferente com a comunidade participando do dia a dia local a partir de vivências que valorizam o intercâmbio de experiências e culturas.

O trabalho de Organizações Não Governamentais (ONGs) nas comunidades no desenvolvimento de um turismo alternativo, revela um outro ator social na configuração da rede do turismo comunitário: o terceiro setor. A atuação desse setor como ator social do turismo vem crescendo nos últimos anos, acompanhando o processo de discussões acerca dos impactos causados pelo turismo convencional e a necessidade de novas formas de organização do turismo. Tem como principal papel a sensibilização, organização e articulação das comunidades na elaboração de novas práticas de turismo, além de ter um papel bastante representativo na captação de recursos.

\section{REDES DE TURISMO DE BASE COMUNITÁRIA}

Ao mesmo tempo em que esse novo modelo de organização do turismo imprime uma nova forma à rede do turismo, busca, também, como estratégia, criar redes que procuram conectar as várias iniciativas que vêm surgindo no mundo todo a partir do século XX. As redes de turismo de base comunitária são redes sociais de contrapoder que, mais do que estratégias de inserção das comunidades no mercado turístico, são estratégias de resistência ao modelo de turismo convencional (BARBOSA, 2011) e de fortalecimento do turismo de base comunitária na luta pelo território e afirmação de suas identidades.

Como exemplo dessas redes pode-se citar a Rede Brasileira de Turismo Solidário e Comunitário (Rede Turisol), e a Rede Cearense de Turismo Comunitário (Rede Tucum). Essas redes articulam um conjunto de comunidades fortalecendo a prática turística comunitária e buscando superar as deficiências por meio do intercâmbio de experiências e de trabalhos coletivos.

A Turisol surgiu, em 2003, a partir da articulação de sete iniciativas de turismo de base comunitária. A rede constitui-se de "diversas organizações no Brasil que desenvolvem projetos de turismo solidário e que buscam, através da união e troca de experiências, fortalecer as iniciativas existentes e despertar outras comunidades para a construção de um turismo diferente" (TURISOL, 2010, p. 9). A rede se consolida em 2007, com sete iniciativas pioneiras. Em 2008, com aprovação de projeto no Edital do Ministério do Turismo de apoio a iniciativas de turismo de base comunitária, o Projeto Bagagem, organização não governamental que trabalha no apoio às iniciativas de turismo de base comunitária, começa a exercer o papel 
de Secretaria-Executiva na gestão e articulação da rede. Com o término do projeto, a rede fica adormecida entre os anos de 2011 e 2014, quando são retomados novos diálogos e articulações que culminaram com o II Encontro da Rede Turisol, em Brasília, em agosto de 2015, no qual participaram comunidades espalhadas por todo o País, ONGs, Academia, agências, operadoras, entre outros atores (TURISOL, 2015), dando nova vida à rede.

A Rede Tucum é "uma articulação de comunidades que se propõe a realizar o turismo comunitário no Ceará, integrado ao fortalecimento da relação entre sociedade, cultura e natureza" (REDE TUCUM, 2013, p. 7). Integra, atualmente, 15 iniciativas que desenvolvem uma proposta de turismo de base comunitária. Essas iniciativas localizam-se ao longo do litoral cearense e compreendem comunidades litorâneas, ribeirinhas, assentamentos rurais, tribos indígenas e Reservas Extrativistas, cada qual com a sua especificidade e autenticidade, mas que são marcadas por um elo em comum: luta pela terra, a afirmação de suas identidades e a resistência à apropriação de seus territórios seja por grupos hoteleiros, equipamentos turísticos ou viveiros de camarão. A rede conta, ainda, com a assessoria institucional de três ONGs (Associação Caiçara de Promoção Humana, Instituto Terramar de Pesquisa e Assessoria à Pesca Artesanal e Associação para o Desenvolvimento Local Coproduzido (Adelco)).

A Rede Tucum trabalha promovendo ações que englobam desde a consolidação da infraestrutura, por meio da melhoria e/ou construção de equipamentos turísticos, sinalização turística, organização de trilhas; mobilização social em torno dos direitos das comunidades tradicionais; e formação dos sujeitos coletivos (PEREIRA; SOUSA, 2010).

Assim, se constituem essas Redes de Turismo de Base Comunitária, de nós heterôgeneos, de multiplicidades de culturas, costumes, saberes, vivências e lutas, mas conectados por elos em comum, por vínculos de reciprocidade que permitem a construção de mecanismo de colaboração entre os nós. Elas têm como núcleo central as comunidades que desenvolvem iniciativas de turismo de base comunitária, e como parceiros ONGs, academia, agências, operadoras, entre outros atores que se identificam com o trabalho e os valores propagados dentro da rede. Compreende, portanto, redes sociais de contrapoder que prioriza as ações coletivas, por meio de uma organização mais horizontal e descentralizada.

Essa diversidade de experiências permite um processo de comunicação por meio do intercâmbio de conhecimentos, vivências e lutas, que dá vida à rede, fortalecendo a organização comunitária e o desenvolvimento de um novo modelo de turismo dentro de cada comunidade. A partir do fortalecimento de cada comunidade cria-se o processo contínuo de realimentação que fortalece a rede e as comunidades em um movimento cíclico. Da mesma forma, caso haja o enfraquecimento de algum nó ou da rede, ocorre um processo de propagação negativa que pode levar ao enfraquecimento da estrutura reticular e das comunidades.

As redes de turismo de base comunitária podem envolver três níveis de colaboração (TOLKACH et al., 2013). O primeiro nível ocorre dentro da comunidade. Os vários grupos que compõem uma determinada comunidade podem experimentar complexas relações de poder, o que variará de acordo com as particularidades de cada comunidade no que se referem ao nível e à forma de organização e as relações sociais nela empreendidas.

O segundo nível ocorre entre a comunidade e outro ator associado, que pode ser tanto público, privado, quanto voluntário (ONGs). Ressalta-se que o turismo de base comunitária vive um conflito enquanto 
modelo de gestão e planejamento da atividade, pois deve combinar tanto operações comerciais, quanto o desenvolvimento comunitário o que gera uma tensão e conflitos de interesse entre os objetivos da comunidade e dos outros atores (TOLKACH et al., 2013).

O terceiro e último nível é a relação entre as várias iniciativas que compõem a rede. As várias comunidades que compõem essas redes, apesar de possuírem elos em comum, que levam ao diálogo e construção de vínculos, são em sua essência heterogêneas e, dessa forma, podem estar baseadas em diferentes modelos de organização e diferentes pontos de vista sobre o turismo de base comunitária (TOLKACH et al., 2013).

Todos esses níveis de colaboração devem ser pensados, analisados e trabalhados na formação e organização das redes de turismo comunitário, no sentido de que em cada nível a rede possa estabelecer um processo de comunicação e relações que permita a criação dentro da rede de um "contexto de significados comum", baseado em valores da organização comunitária, economia solidária, cooperação, equidade e justiça. Ainda, que permita que os diversos nós envolvidos construam um sentimento de identidade e pertencimento enquanto membro da rede para que possa propagar esse significado comum e fortalecer a rede.

\section{CONSIDERAÇÕES FINAIS}

O fenômeno do turismo pode ser entendido como uma complexa rede de relações na qual fazem parte diversos atores sociais que têm como elemento de conectividade o deslocamento de pessoas em seu momento de lazer. A maneira pela qual esses atores interagem vai influenciar diretamente na forma como essa atividade se desenvolverá nas comunidades receptoras. Nesse sentido, o turismo convencional e o turismo de base comunitária se diferenciarão pelo modo como esses atores se relacionam entre si, as relações de poder existentes, o papel que cada um exerce no planejamento e desenvolvimento da atividade turística e os valores e significados que são propagados no interior da rede construída a partir do turismo.

Dentro dessa complexa rede de relações que envolve o turismo de base comunitária, as iniciativas que vêm emergindo nas últimas duas décadas buscam como mecanismo de fortalecimento das experiências a construção de redes. Estas constituem redes sociais de contrapoder que se assemelham às redes de movimentos sociais por formarem uma organização coletiva para o fortalecimento de comunidades na busca por um outro modelo de atividade turística. Elas se caracterizam pela horizontalidade, descentralização e a não linearidade de suas estruturas. Trabalha com a valorização das heterogeneidades e autonomia dos pontos, e se conectam por elos em comum como a luta pela terra, a afirmação de suas identidades, valorização da cultura e das atividades tradicionais.

Caracterizam-se, também, pela ação de ONGs como atores sociais essenciais no processo de fortalecimento e articulação da construção do turismo de base comunitária, exercendo, muitas vezes, o papel de mediadores do processo organizativo. Nessas redes, as conexões estabelecidas se dão por meio da comunicação que cria um processo de construção de significado e valores que se propagarão dentro da rede, permitindo o fortalecimento desta e de seus nós, que possibilita a luta por um outro modelo de organização do turismo. 
Vale ressaltar, contudo, que não se esgotam neste trabalho as discussões acerca das redes de turismo de base comunitária, tendo em vista o papel de cada nó que compõe a rede, os processos que os conectam e o significado construído dentro delas, considerando os diferentes níveis de colaboração, é um tema que necessita ser aprofundado e analisado empiricamente. Além de que, novas reflexões e questionamentos podem surgir a partir das ponderações aqui apresentadas.

\section{REFERÊNCIAS}

BARBOSA, L.M. Redes de territórios solidários do turismo comunitário: políticas para o desenvolvimento local no Ceará. 16of. (Dissertação de Mestrado) - Mestrado Acadêmico em Geografia, Universidade Estadual do Ceará, Centro de Ciências e Tecnologia. Fortaleza: Universidade Estadual do Ceará, 2011.

BURGOS, A.; MERTENS, F. A perspectiva relacional na gestão do turismo de base comunitária: o caso da Prainha do Canto Verde. Caderno Virtual de Turismo. Rio de Janeiro, v. 15, n.1, p. 81-98, abr. 2015.

BURSZTYN, I.; BARTHOLO, R.; DELAMARO, M. Turismo para quem? Sobre caminhos de desenvolvimento e alternativas para o Brasil. In: BARTHOLO, R.; SANSOLO, D. G.; BURSZTYN, I. Turismo de Base Comunitária: diversidades de olhares e experiências brasileiras. Rio de Janeiro: Letra e Imagem, 2009. p. 76-91.

CAPRA, F. A teia da vida. São Paulo: Cultrix, 1996.

. As conexões ocultas. São Paulo: Cultrix, 2002.

CASTELLS, M. A sociedade em rede. São Paulo: Paz e Terra, 1999.

. Redes de indignação e esperança: movimentos sociais na era da internet. Zahar, 2013.

CORIOLANO, L. M. O turismo comunitário no nordeste brasileiro. In: BARTHOLO, R.; SANSOLO, D. G.; BURSZTYN, I. Turismo de base comunitária: diversidade de olhares e experiências brasileiras. Brasília: Letra e Imagem, 2009. p. 277-288.

DIAS, L. C. Redes: emergência e organização. In: I. CASTRO, E.; GOMES, P. C.; CORRÊA, R. L. Geografia: conceitos e temas. Rio de Janeiro: Bertrand, 1995.

FRATUCCI, A. C. A dimensão espacial nas políticas públicas brasileiras de turismo: as possibilidades das redes regionais de turismo. 308f. Tese (Doutorado em Geografia) - Universidade Federal Fluminense. Niterói: Universidade Federal Fluminense, 2008.

IRVING, M. D. Reinventando a reflexão sobre turismo de base comunitária. In: BARTHOLO, R.; SANSOLO, D. G.; BURSZTYN, I. (Org.). Turismo de base comunitária: diversidade de olhares e experiências brasileiras. Brasília: Letra e Imagem, 2009. p. 108-121.

MARTINHO, C. Redes: uma introdução às dinâmicas da conectividade e da auto-organização. Brasília: WWF-Brasil, 2003.

PEREIRA, R. M.; SOUSA, V. F. Rede Cearense de Turismo Comunitário: turismo e resistência na zona costeira cearense. São Paulo: Série Turisol de metodologias de turismo comunitário, 2010.

ROVERE, M. R. Redes en Salud; un nuevo paradigma para el abordaje de las organizaciones y la comunidad. Rosario: Ed. Secretaría de Salud Pública/AMR, Instituto Lazarte, 1999. 
SANSOLO, D. G.; BURSZTYN, I. Turismo de base comunitária: potencialidade no espaço rural brasileiro. In: BARTHOLO, R.; SANSOLO, D. G.; BURSZTYN, I. Turismo de Base Comunitária: diversidade de olhares e experiências de turismo Brasília: Letra \& Imagem, 2009. p. 142-161.

SANTOS, M. O Retorno do Território. Clacso. Buenos Aires, Ano VI, n. 16, jun. 2005.

- A natureza do Espaço: técnica e tempo, razão e emoção. 4. ed. São Paulo: Editora da Universidade de São Paulo, 2006.

SCHERER-WARREN, I. Das mobilizações às redes de movimentos sociais. Sociedade e Estado, v. 21, n. 1, p.109-130, 2006.

. Redes Sociais: trajetórias e fronteiras. In: DIAS, L. C.; SILVEIRA, R. L. L. Redes, sociedades e territórios. Santa Cruz do Sul: Edunisc, 2007. p. 29-50.

TEIXEIRA, S. M. O desafio da gestão das redes de políticas. In: VII Congresso Internacional del CLAD sobre la Reforma del Estado y de la Administracion Publica. Lisboa, Portugal: CLAD, 2002.

TOLKACH, D.; KING, B.; PEARLMAN, M. An Attribute-Based Approach to Classifying Community-Based Tourism Networks. Tourism Planning \& Development, v. 10, n. 3, p. 319-337, 2013.

TUCUM. Caderno de Normas da Rede Tucum - Rede Cearense de Turismo Comunitário. Rosa Martins (Org.). Fortaleza: Instituto Terramar, 2013.

TURISMO, C. de. De Mumbai a Porto Alegre - Quem realmente se beneficia com o turismo. Mumbai: 4ํㅜórum Social Mundial, 2004.

TURISOL. I Encontro da Rede Brasileira de Turismo Solidário e Comunitário. Turisol, 2010. . Il Encontro da Rede Brasileira de Turismo Solidário e Comunitário. Brasília: Turisol, 2015. 